\title{
P-92
}

\section{Antioxidant Activitivies of Standardized Extracts of Gynura Segetum's Leaf}

\author{
Lay-Jing Seow*, Hooi-Kheng Beh, Amirin Sadikun and Mohd Zaini Asmawi
}

School of Pharmaceutical Sciences, Universiti Sains Malaysia, Penang, Malaysia; E-mail: layjing80@gmail.com

Gynura segetum, family Compositae (Asteraceae) is a cultivated species and known to possess various medicinal properties for treatment of cancer, inflammation, diabetes, hypertension and other skin afflictions. The antioxidant activities were studied using 1,1-diphenyl-2-picrylhydrazyl (DPPH) scavenging and $\beta$-carotene-linoleate model system. The amounts of total phenolic and flavonoid in the extract were also determined. The ethyl acetate fraction consistently exhibited the highest antioxidant activity based on the tests performed. The ethyl acetate fraction was potent at DPPH scavenging activity with the lowest $\mathrm{EC}_{50}$ $(91.65 \mathrm{ug} / \mathrm{ml})$. Antioxidant activity based on the bleaching rate of $\beta$-carotene showed percentage inhibition of $81 \%$ comparable to Quercetin $(94 \%)$ at $250 \mathrm{ug} / \mathrm{ml}$. The total phenolic and flavonoid content of ethyl acetate fraction were $214.9 \mathrm{ug} / \mathrm{ml} \mathrm{gallic}$ acid equivalent of extract and $67.5 \mathrm{ug} / \mathrm{ml}$ quercetin equivalent of extract, respectively. The results of this study suggested the correlation between the antioxidant activity potential and total phenolic and flavonoid contents of the ethyl acetate fraction. Phenolic compounds present in the plants may be a major contributor of antioxidant activities. In conclusion, the ethyl acetate fraction of Gynura segetum's leaf is a potential source of natural antioxidants with potent antioxidant activities.

Keywords: Gynura segetum, antioxidant, DPPH, beta-carotene. 